\title{
Alunos da Faculdade Zumbi dos Palmares: reinventando o pertencimento racial $^{1}$
}

\author{
Marla Andressa de Oliveira Santos * \\ Marília Pinto de Carvalho **
}

* Mestra em educação pela Faculdade de Educação da Universidade de São Paulo.

** Profa. Dra. da Faculdade de Educação da Universidade de São Paulo.

\begin{abstract}
Resumo: 0 artigo discute a influência da vivência do ensino superior na ressignificação do pertencimento racial de estudantes universitários negros. Em pesquisa qualitativa desenvolvida entre 2009 e 2011, tomaram-se como estudo de caso os alunos da Faculdade Zumbi dos Palmares (FZP), instituição localizada na cidade de São Paulo, ligada ao movimento negro. A FZP foi criada em 2003 com o objetivo de oferecer alternativa de acesso àformação em nível superior e proporcionar aos estudantes negros um espaço de construção e afirmação da identidade racial por meio de currículos marcados pela transversalidade. As análises obtidas identificaram, para além do discurso da FZP, o trabalho e o consumo como elementos importantes da ressignificação da pertença racial para aqueles alunos.
\end{abstract}

Palavras-chave: Relações Raciais. Negros. Pertencimento Racial. Ações Afirmativas. Ensino Superior.

Este artigo apresenta parte dos resultados da dissertação de mestradointitulada O Pertencimento Racial de Universitários Negros da Faculdade Zumbi dos Palmares, financiadapela Coordenação de Aperfeiçoamento de Pessoal de Nível Superior e defendida em abril de 2012, na Faculdade de Educação da Universidade de São Paulo, sob orientação da Profa. Dra. Marília Pinto de Carvalho. 
INTRODUÇÃO

A partir dos anos 2000, no governo Luis Inácio Lula da Silva (2003-2010), com forte influência dos movimentos sociais, constata-se o aumento das políticas públicas voltadas para grupos específicos da população nas quais são adotados recortes etários, de renda, de sexo/gênero ou de raça/etnia como forma de reparar desequilíbrios sociais. Tendo o governo brasileiro reconhecido, ainda na década de 1980, a existência do racismo e o seu lugar como parte integrante dos mecanismos de perpetuação das injustiças sociais, uma série de políticas de promoção de igualdade racial começa a ser desenvolvida em âmbito federal, por meio da criação de estruturas internas nos setores executivos, consultivos e de formulação e monitoramento de políticas em diferentes áreas, como saúde, trabalho, agricultura e educação (RIBEIRO, 2009; MOEHLECKE, 2009).

Dentre essas políticas, a área da educação, considerada estratégica, recebeu considerável destaque. Para os movimentos negros, mudanças estruturais na política educacional são necessárias como forma não só de garantir o acesso à educação a toda população como de construir uma nova lógica social sem os vícios do racismo (SILVERIO,SOUSA, 2010; HERINGER, 2001,2002). Neste sentido, as duas ações mais representativasimplementadas, até o final da década de 2010, foram a Lei 10.639/2003, que determina a obrigatoriedade da inclusão do ensino de história e cultura afrobrasileira e africana nos currículos escolares; e o sistema de reserva de vagas para o acesso de estudantes negros ao ensino superior adotado nos vestibulares de parte das universidades federais.

A importância dessa última ação reside no fato de que mesmo com o aumento da escolaridade da população brasileira e com as melhoras significativas nos índices de educação dos negros nas últimas duas décadas, ainda é notória sua maior vulnerabilidade em relação ao acesso e permanência na escola. Esta desvantagem vem paulatinamente se reduzindo graças a políticas de universalização do ensino básico e de distribuição de renda, como o Bolsa Família. Porém, no ensino superior é gritante a diferença de acesso, o que demonstra que nos níveis mais altos de ensino ainda resiste um gargalo bastante estreito no percurso educacional dos jovens negros(SILVA; SILVA; ROSA, 2009).

Segundo dados apresentados pela Síntese dos Indicadores Sociais (IBGE, 2010, p. 235), enquanto $62,6 \%$ dos jovens brancos na faixa etária dos 18 
aos 24 anos frequentavam algum curso superior, apenas $31,8 \%$ dos pardos e $28,2 \%$ dos pretos na mesma faixa etária estavam neste nível de ensino, ou seja, a porcentagem de universitários entre os brancos era praticamente 0 dobro daquela encontrada entre os jovens pardos e pretos. Considerando que a população negra, devido a desvantagens educacionais históricas, poderia ingressar no ensino superior tardiamente, observamos também a faixa etária seguinte, acima dos 25 anos, e ainda assim não encontramos melhor cenário. Segundo os dados da PNAD (Pesquisa Nacional por Amostragem de Domicílios) de 2009, pretos e pardos representavam apenas 4,7\% e 5,3\% dos graduados respectivamente. Entre os brancos, a porcentagem era de $15 \%$, ou seja, o triplo.

Esse cenário de sub-representação dos estudantes negros no ensino superior se manteve durante os anos de 1999 a 2009, mesmo com a criação de programas de incentivos com viés socioeconômico como o PROUNI (Programa Universidade para Todos) e FIES (Fundo de Financiamento ao Estudante do Ensino Superior), implementados concomitantemente ao sistema de cotas adotado recentemente pelas universidades federais, e a expressiva expansão no número total de matrículas alavancadas pelas instituições de ensino privadas. Isso demonstra que "diante das lacunas que vieram se acumulando ao longo das gerações, tal incremento somente pode ser visto como sumamente insuficiente" (PAIXÃO et al., 2011, p. 231).

Ainda que restrita, a elevação dos níveis de educação da população negra, conforme defendem os movimentos antirracistas, pode repercutir na sociedade de maneiras que merecem ser atentamente consideradas. $\mathrm{Na}$ perspectiva de instalar em nossa sociedade relações mais justas e igualitárias, entender como a população negra significa (ou ressignifica) as relações raciais ao acessar tais níveis de formação se constitui em exercício na tentativa de verificar como as ações afirmativas na área da educação podem modificar a relação de pertencimento racial desses estudantes e como esse pertencimento pode, por sua vez, modificar os significados historicamente construídos e socialmente disponíveis.

Em estudo concluído em 2012, problematizamos essa relação entre acesso ao ensino superior e a constituição do pertencimento racial de jovens universitários autoclassificados negros, a partir da observação de uma experiência inovadora empreendida por uma organização não governamental paulista $^{2}$ vinculada aos movimentos negros. Essa organização, de certo, transcendeu a reivindicação do próprio movimento por acesso a formação

ONG Afrobras (Sociedade Afrobrasileira de Desenvolvimento Sociocultural). 
superior ao criar, ela própria, uma instituição de ensino. 0 projeto pedagógico dessa instituição foi pensado para acolher os estudantes negros e, além da formação acadêmica, proporcionar-lhes um espaço de construção e afirmação da identidade racial por meio de um currículo marcado pela transversalidade, no qual a temática racial estivesse no cerne das discussões.

Por meio dessa pesquisa, esperávamos conhecer as percepções raciais apresentadas pelos alunos negros e averiguar como, no entendimento deles, o discurso de valorização da raça negra e de seus elementos apresentados pela instituição influenciavam a maneira como significavam a sua pertença racial. Tínhamos como hipótese inicial que a proposta curricular e ideológica desse projeto poderia fortalecer a identidade racial e definir um pertencimento que contribuiria para a reelaboração de uma concepção de cidadania por parte desses alunos. Isso refletiria em mudanças tanto nas relações sociais cotidianas quanto institucionais, o que seria um passo importante para o fim da manutenção do racismo em nossa sociedade.

Partimos da noção de pertencimento racial enquanto crença subjetiva na qual os indivíduos pensam em si mesmos como membros de uma coletividade na qual compartilham valores, anseios e aspirações em um espaço-tempo comum e que implica comprometimento ativo com um projeto que vá ao encontro desses anseios (BURITY, 2001; MOURÃO, 2005; AMARAL, 2006). Assim, nos propusemos a investigar como as novas práticas propostas pelo projeto diferenciado da Faculdade Zumbi dos Palmares implicam na definição de identidade racial e, consequentemente, na construção de um pertencimento racial - como o entendemos aqui - de seus alunos negros. O pertencimento racial mais do que posicionar o indivíduo em um grupo, posiciona o indivíduo por um grupo e pressupõe solidariedade não prevista pela identidade racial. Esperávamos com esse estudo observar a existência ou não de uma reinvenção da concepção de cidadania por parte desses alunos, bem como padrões de interação com odebate racial, de relacionamento entre os próprios alunos e entre eles e a sociedade.

Entre os anos de 2010 e 2011, a investigação foi realizadacom alunos da FZP autodeclarados negros, que cursavam a partir do quinto semestre letivo, sem delimitação de sexo ou idade. Em uma primeira etapa, foram realizadas várias visitas de observação a fim de conhecer a rotina da instituição. A segunda etapa compreendeu entrevistas individuais com representantes da instituição e um grupo de cinco alunos: três homens e duas mulheres, matriculados nos cursos de direito e administração de empresas, todos autodeclarados negros, com idades entre 22 e 33 anos. 


\section{A Faculdade Zumbi dos Palmares}

Integrante do movimento negro, a ONG Afrobras, ainda na década de 1990, mantinha no estado de São Paulo um projeto no qual oferecia a jovens negros e carentes um curso preparatório para o vestibular e pleiteava, junto a instituições de ensino privadas, bolsas de estudos para as vagas remanescentes e ociosas nessas instituições. Com o passar do tempo, os responsáveis por esse projeto constataram que era grande a evasão dos beneficiados pelas bolsas. Entre as justificativas para essa evasão, os alunos apontavam o mau atendimento dispensado pelos professores, a dificuldade em acompanhar o programa de estudos, a discriminação por parte dos colegas, a falta de recursos para custear a rotina acadêmica (material didático e transporte) e o desconforto pela evidente diferença de classe frente aos demais alunos. Essas condições indicavam um ambiente nada acolhedor a esses estudantes. Como forma de reverter essa situação, a Afrobas decidiu não mais solicitar bolsas em outras instituições e criar uma faculdade que fosse pensada e preparada para atender às necessidades desses alunos.

Assim, em meio aos debates sobre a viabilidade de ações afirmativas de cunho racial nas universidades públicas brasileiras, surgiu a Faculdade Zumbi dos Palmares, criada em 2003 com a pretensão de ser um divisor de águas no movimento de inclusão social dos negros. Organizada para ser uma faculdade comunitária, sem fins lucrativos, a FZP aspirava aincorporar em sua ação conceitos relacionados à promoção da igualdade racial que estimulassem a criação de um referencial positivo de negro e de sua pertença racial,por meio de um resgate histórico e cultural da realidade do negro brasileiro. Tais conceitos também estimulariamuma consciência política das dificuldades criadas e mantidas pelo racismo, bem como da importância da fortificação dos laços comunitários com os seus pares para a redução das desigualdades sociais.

As informações utilizadas a seguir para descrever a faculdade, suas atividades, projeto e histórico são baseadas em documentos disponibilizados no site ${ }^{3}$ da própria faculdade e/ou informações fornecidas em entrevista realizada com representante designado pela instituição ${ }^{4}$. Isto posto, esclarecemos a necessidade de que algumas informações sejam relativizadas, dada a relação da informante com a instituição.

http://www2.zumbidospalmares.edu.br/.

A Profa. Lina Moreira, coordenadora e docente do curso de publicidade, e também responsável pela coordenação e do processo seletivo, foi a principal representante designada para apresentar a instituição e seu projeto durante a pesquisa de campo. 
Se no início de seu funcionamento a FZP oferecia apenas o curso de administração, atualmente a faculdade já possui cerca de 2000 alunos, sendo $85 \%$ deles autodeclarados negros ${ }^{5}$, distribuídos nos cursos de administração, pedagogia, publicidade e propaganda, tecnologia em transportes e direito. Desde o ano de sua criação, o curso de direito é reconhecido pelo Ministério da Educação e tema aprovação e recomendação da Ordem dos Advogados do Brasil, justamente por ter o objetivo explícito de formar advogados atentos à questão racial ${ }^{6}$. Preocupada em garantir a permanência dos alunos até à conclusão do curso e em atingir o público desejado, o projeto da FZP determinava, além da reserva de $50 \%$ das vagas para alunos negros, que as mensalidades fossem inferiores a um salário mínimo, reconhecendo a notória relação entre raça e classe/renda (HERINGER, 2001,2002).

Ao ser posto em prática, esse projeto tencionava se contrapor a alguns paradigmas recorrentes na sociedade brasileira. De acordo com seus objetivos institucionais 7 , a FZP se propunha a romper com a ideia alimentada pelo preconceito de que existe um lugar para o negro em nossa sociedade: o lugar da subalternização no qual as variáveis raça e classe se encontram, delegando aos negros os postos de trabalho com menor qualificação, rendimento e prestígio, além de outros tantos estereótipos que ainda povoam o imaginário popular. Ao reproduzir objetivos comuns defendidos principalmente pelo movimento negro, a FZP acabou por ilustrar um momento da história brasileira quando

o negro está procurando, por vias político-ideológicas explicitadas, construir uma identidade positiva do grupo, com forte inspiração em uma classe média emergente, à busca da conquista de espaços sociais que até então lhe tem sido vedados, isto é, o negro quer ir além dos espaços que historicamente a sociedade brasileira lhe tem reservado [...] A sua grande inspiração é o modelo americano, embora procure preservar e consolidar uma identidade nacional, desde que ele não descarte o negro como seu elemento constituinte (PEREIRA, 2002, p. 69).

Com essa breve introdução, podemos dizer que a Faculdade Zumbi dos

5 Essa composição racial do corpo discente da FZP se manteve desde o seu primeiro ano de funcionamento. A instituição coleta informações sobre a autoclassificação racial dos alunos durante o processo seletivo e também ao longo do ano com todos os alunos matriculados.

6 Nota publicada pelo Conselho Federal da Ordem dos Advogados do Brasil (OAB) por meio de sua Comissão Nacional de Ensino Jurídico, emitindo parecer favorável apenas à criação do curso de Direito da Faculdade Zumbi dos Palmares, em São Paulo, em 04/julho/2007. Na mesma ocasião, outros 19 cursos aprovados pelo MEC foram reprovados pela OAB.

http://www2.zumbidospalmares.edu.br/index.php?option=com_content\&view=article \&id=65\&ltemid=58 Também foram consideradas informações e opiniões coletadas junto a representantes da FZP na mídia em geral. 
Palmares é, de alguma forma, uma resposta ao momento histórico e social de quando foi criada. Ou seja, momento de fortalecimento dos movimentos sociais e do movimento negro em especial, da reafirmação de uma identidade etnicorracial, da reivindicação do acesso a direitos humanos essenciais como a educação, da expansão do ensino básico, do movimento dos cursinhos pré-vestibular, da expansão do ensino superior, principalmente privado, e do reconhecimento da relação entre raça e classe. Todos esses são fatores que explicam a existência de uma experiência como a FZP em nossa sociedade.

Uma instituição que acredita expressar diversos anseios da população negra, pela sua proposta enquanto ação afirmativa sem vínculos governamentais, já seria um interessante objeto de investigação. Mas ao apresentar uma proposta inédita no cenário brasileiro que aposta na reconstrução de uma identidade racial e cultural atrelada a um projeto pedagógico e profissionalizante como plataforma mobilizadora para a conquista da cidadania plena, a FZP nos oferece, ainda, a oportunidade de estudar as relações raciais por um viés bastante diferenciado.

Para identificar os significados e as construções acerca do que é ser negro, tanto no discurso dos estudantes quanto no discurso institucional da FZP, recorremos a categorias e conceitos já definidos na literatura que problematizam as relações raciais e a questão das identidades etnicorraciais brasileiras. Inicialmente, buscamos o conceito analítico ${ }^{8}$ de raça social descrito por Guimarães (1999, p. 67), no qual o autor propõe que as raças sejam entendidas como construções sociais capazes de orientar as ações humanas ao classificar e identificar indivíduos de forma eficaz na manutenção de diferenças e privilégios.

Ora, no Brasil, a teorização de "raças", definidas como formas de classificar e identificar que podem produzir comunidades, associações ou apenas modos de agir e pensar individuais, constitui, para a sociologia, o instrumento apto a revelar condutas políticas e instituições que, ainda que inadvertidamente, conduzem à discriminação sistemática e à desigualdade de oportunidades e de tratamento entre grupos de cor.

Os grupos de cor, enquanto conceito nativo, atendem a forma recorrente de auto e hetero classificação utilizada no cotidiano da população brasileira com base em critérios fenotípicos que são historicamente carregados de valores e significados hierarquizantes. Isso demonstra a filiação deste conceito a uma ideologia racial, pois é somente no interior dessa ideologia que a atribuição de valores a traços fenotípicos faz sentido (GUIMARÃES, 1999, 2003). Esse

8 Os conceitos analíticos permitem a crítica de um determinado conjunto de fenômenos e só fazem sentido dentro de uma teoria específica, enquanto os conceitos nativos são aqueles utilizados no mundo prático (GUIMARÃES, 2003). 
conceito, presente nas relações raciais brasileiras desde a escravidão, está hoje na base das concepções raciais no país. É de tal forma "naturalizado" que é mantido por órgãos oficiais como forma de inquirir a população sobre sua classificação racial nos censos e pesquisas. Desde 1972, o IBGE colhe dados da população considerando categorias de cor. Segundo Araújo (1987, p. 15), “na sociedade brasileira a cor é a metáfora, a categoria mais frequentemente acionada para demarcar diferenças e desigualdades com base na raça".

Por se apoiarem em uma ideologia racial, as concepções de cor e também de embranquecimento ocupam lugar central, caracterizando a peculiaridade do racismo brasileiro. Muitas vezes negado pelo ideário comum, o racismo assim como a discriminação racial são frequentemente amenizados e descritos como "preconceito" na linguagem cotidiana. Essa preferência, assim como a negação da existência das raças, demonstra quão entranhada no senso comum brasileiro está a ideologia da democracia racial (GUIMARÃES, 1999; SCHWARCZ, 2001). O racismo entendido como um fenômeno social, que compreende a fundamentação ideológica das práticas preconceituosas e discriminatórias dos indivíduos racistas, mesmo não mais justificado por fundamentos biológicos, apoia-se sempre na crença da existência de um gradiente natural de valor relacionado a determinadas formas físicas e étnicas.

A ideologia racista, portanto, atua no sentido de justificar moralmente o preconceito, a discriminação e as situações crônicas de desigualdade verificadas entre as pessoas fenotípica e culturalmente diferentes. Ou seja, a ideologia racista adestra os olhos e a mente de toda a sociedade para a aceitação acrítica da coincidência verificada entre as hierarquias de classe e as hierarquias étnicas e raciais (PAIXÃO et al., 2011, p. 21).

Por considerarmos aqui a influência de uma ação política e pedagógica na ressignificação de valores e discursos raciais, faz-se necessário conceituarmos esse tipo de ação, principalmente pelo desencontro que ainda se percebe acerca do que sejam as ações afirmativas. Segundo Joaquim Barbosa Gomes (2001, p. 6):

as ações afirmativas consistem em políticas públicas (e também privadas) voltadas à concretização do princípio constitucional da igualdade material e à neutralização dos efeitos da discriminação racial, de gênero, de idade, de origem nacional e de compleição fisica. Impostas ou sugeridas pelo

Estado, por seus entes vinculados e até mesmo por entidades puramente privadas, elas visam a combater não somente as manifestações flagrantes de discriminação, mas também a discriminação de fundo cultural, estrutural, enraizada na sociedade. De cunho pedagógico e não raramente impregnadas de um caráter de exemplaridade, têm como meta, também, o engendramento de transformações culturais e sociais relevantes, inculcando nos atores sociais a utilidade e a necessidade da observância dos princípios do pluralismo e da diversidade nas mais diversas esferas do convívio humano. 
É importante destacar que o sistema de cotas é uma modalidade de ação afirmativa dentre uma pluralidade de formatos existentes e menos utilizados no Brasil.

A experiência da Faculdade Zumbi dos Palmares se processa em meio a uma teia de relações sociais na qual os aspectos raciais são cada vez mais evocados pela Academia e pela sociedade em geral, para explicar e denunciar estruturas discriminatórias consolidadas em nossa sociedade que, por meio de vários mecanismos institucionais, mantêm os negros em posição de preterimento em relação à parcela branca da população. Com a perspectiva de mudar esse contexto, os movimentos negros têm agido em diferentes instâncias, desenvolvendo ações que reconstruam, perante Estado e sociedade, a imagem de um cidadão negro com qualidades positivas compatíveis com os aspectos modernos da sociedade, um sujeito de direitos que busca a igualdade, mesmo que para alcançá-la precise antes afirmar ainda mais a sua diferença.

Concomitante à mobilização das organizações negras, o crescimento econômico registrado no país, principalmente na última década, tem proporcionado algumas mudanças na vida cotidiana da população, favorecendo outra forma de inclusão da população negra nos modos de produção e consumo capitalistas. A abertura de novos postos de trabalho e a facilitação do crédito financeiro potencializaram o poder de compra de uma parcela da população que alçada ao patamar de consumidora, passa a vislumbrar de forma inédita a condição de cidadania plena ${ }^{9}$. A dureza de uma situação na qual o acesso a direitos básicos está diretamente relacionado ao poder de consumo é um traço marcante de nossa sociedade que não pode ser ignorado quando tratamos de desigualdades raciais, pois há uma relação direta entre classe e raça que se mantém forte e contemporânea (GUIMARÃES, 2002; MUNANGA, 1999; TELLES, 2003; HERINGER, 2001, 2002; COSTA, 2002; SANSONE, 2000). Consideraresses aspectos no debate sobre as desigualdades raciais é, portanto, relevante, pois para Souza (2005, p. 56),

o mercado e o Estado não são apenas grandezas materiais regidas por critérios de eficácia formal, mas sim materializações de "concepções de mundo" com uma hierarquia material peculiar, [...] esta é a forma especificamente moderna de construir distinções sociais e de legitimá-las.

Ao que parece, a inclusão da população negra nessa sociedade regida pelo mercado tem seguido dois caminhos paralelos: no primeiro, a negritude,

9 Não consideramos cidadania e consumo como sinônimos. 0 consumo é um aspecto da cidadania em nossa sociedade que está relacionado ao acesso a bens e serviços que conferem qualidade de vida à população. 
a cultura negra e o étnico são apropriados pelo mercado e transformados em produtos destinados a atender a uma demanda específica ou cativar uma clientela emergente ávida por consumir; e no segundo, se mantêm as características de consumo influenciadas pela lógica de branqueamento, na qual o mercado tem uma cor - a branca - que é reforçada ou "emprestada" àqueles que consomem seus produtos. Essas duas perspectivas coexistem influenciando os processos de socialização ${ }^{10}$ dos indivíduos que lidam com elas de acordo com o momento específico em que se encontram no desenvolvimento de sua identidade racial.

Em seus últimos recenseamentos, o próprio IBGE atribuiu o aumento expressivo do número de pessoas que se declararam pretas e pardasà atuação marcantedos movimentos negros nas últimas décadas. Esse fenômeno pode ser notado desde o final da década de 1990 e tem se acentuado com o passar dos anos. Segundo a Síntese dos Indicadores Sociais (SIS) 2010 (IBGE, 2010), entre os anos de 1999 e 2009, o percentual de pretos na população brasileira aumentou de $5,4 \%$ para $6,9 \%$, e os pardos, que antes representavam $40 \%$ da população, já somam 44,2\%. Com isso a população negra no Brasil alcançou $51,1 \%$, enquanto a população branca diminuiu de $54 \%$ para $48,2 \%$ no mesmo período.

Na última década, a soma dos fatores crescimento econômico, valorização social da identidade negra e políticas de ação afirmativa têm definido um contexto diferenciado para as relações raciais no país. À influência que esse contexto possa ter na vida dos negros em geral, os alunos da Faculdade Zumbi dos Palmares soma ainda a condição de participar de um projeto em que esses fatores são potencializados, o que, como foi possível constatar durante as visitas de campo e entrevistas, exerce considerável pressão sobre a maneira como eles assimilam a sua realidade e moldam a sua identidade racial para então construírem um pertencimento racial que dialogará diretamente com o contexto social mais amplo.

\section{AS BASES DO PERTENCIMENTO RACIAL}

Dentro de seu plano pedagógico e institucional divulgado em documentos oficiais, no site ${ }^{11}$ da faculdade e em declarações e entrevistas do diretor da

10 Segundo Grigorowitschs (2008, p. 37), “"processos de socialização', no plural, e não no singular, e nem simplesmente "socialização", é uma concepção extraída de Simmel que deriva do seu entendimento de processos sociais, que, pensados no plural, enfatizam o caráter de mobilidade e dinâmica das interações sociais".

${ }_{11}$ http://www2.zumbidospalmares.edu.br/ 
instituição veiculadas pela mídia, a FZP tem bem definido um projeto de negro. Na rotina da faculdade, esse projeto precisa ser conciliado com as centenas de projetos pessoais e expectativas profissionais de seus alunos, cada um deles partindo de diferentes significados de ser negro, cidadão e profissional. Cada um dos estudantes entrevistados se encontrava em um momento particular de autodefinição de sua identidade e pertencimento racial. Alguns elaboravam e verbalizavam as concepções do que os tornavam negros

\begin{abstract}
Não gosto nem de ouvir falar "eu sou moreno" [...] Acho que teria que ter uma mudança no contexto da vida dessa pessoa para ela começar a dizer "sou negro e está ótimo, não tem um problema nisso". Só que hoje não tem como eu chegar para uma pessoa dessa e falar que ela tem que se assumir como negra se a imagem do negro para ela é depreciada, se ela vê o negro numa posição inferior. Ninguém quer estar em uma posição inferior. Então para ela é mais confortável falar que ela é morena [...] Para mim vai muito da ideia. Eu particularmente não me vejo como negro pelo meu tom de pele, eu busco toda a história que tem por trás de mim. Eu me vejo mais pelas ideias que eu sigo, é mais pela minha cabeça, não é muito pelo tom de pele, não. (Daniel ${ }^{11}$, 22 anos, estudante de administração.)
\end{abstract}

Acho que a informação está chegando melhor para nós, mesmo que eles tentem vetar. 0 muro está furando, está quebrando, não tem jeito, não tem o que fazer para não cair e ficar o resto da vida. Nada disso vai ser eterno. - [sobre a luta contra discriminação racial](Vitor, 33 anos, estudante de administração.).

Outros estudantes demonstraram passar por um processo de descobertas e reconhecimento da positividade da sua estética negra. Esse processo, que não é linear, destaca-se nas falas de Ana e Carla, que mesclam a expressão de sua identidade negra com a utilização de termos pejorativamente racistas, o que evidencia as experiências de socialização e pertencimento racial que elas tiveram ao longo da vida.

Quando eu usava trança, eu tinha uns nove, dez anos, até os 14 anos. Eu fazia aquelas tranças enraizadas ou então deixava soltas e colocava uns tererês. Era minha madrinha que fazia, então andei sempre muito de trança. Depois andei bastante de escova e teve a época que comecei a andar com o cabelo enrolado, assim, e não parei mais.[...] Eu achava que meu cabelo ficava mais bonito. Mas depois que ele começou a ficar um encaracolado [quando ela entrou na faculdade] bem mais bonito assim, aí eu fui criando essa identidade, daí dava para colocar presilha, lenço no cabelo, ficava super bonito (Carla, 22 anos, estudante de direito.).

\title{
[...] Então fez essa mistura, eu vim com a cor da minha mãe e o cabelo do meu pai, meu irmão já veio um pouco mais claro com o cabelo um pouco... um pouco não, bem melhor. [...] Eu tenho amigos brancos que eu considero negros porque têm o cabelo ruim, crespo mesmo. Se tem o nariz achatado é negro, se tem a boca grossa, já era. Se você não é, você tem o "pé lá na cozinha". \\ [...] Para mim é assim, se a pessoa passou do meio dia, tem o cabelo enrolado, tem o olho meio avermelhado, lábio carnudo, nariz um pouco achatado e curte um sambinha, para mim já é negro (Ana, 26 anos, estudante de administração).
}

${ }^{12}$ A fim de preservar a identidade de todos os entrevistados os nomes utilizados aqui são fictícios. 
E houve ainda o caso de Caio, aparentemente inclinado a construir estratégias de enfrentamento à trama de preconceitos de classe e raça na busca pela cidadania.

[...] O máximo que eu posso fazer é manter uma posição, então é assim: ainda exista preconceito, existe uma máscara. Às vezes ele é explicito, às vezes não é, depende muito. Depende também da atitude que eu vou tomar. Eu poderia me revoltar e quebrar as coisas, e muita gente espera que a gente faça isso. Ou simplesmente eu posso agir com tudo que eu aprendi na minha vida. Posso pegar tudo que eu aprendi na Zumbi e usar isso ao meu favor, usar com o poder da justiça. (Caio,

24 anos, estudante de direito)

A forma como o projeto da FZP foi elaborado e vem sendo desenvolvido privilegia alguns aspectos que, na fala dos entrevistados, foram também apontados como peças-chave na construção do pertencimento racial. Essa correlação nos deu pistas sobre em que medida os alunos e a instituição alinham suas expectativas e concepções. A questão da militância, tanto no movimento negro quanto partidária, apesar de ser um meio onde a FZP possui fortes relações, não foi apontada como relevante naquele contexto pelos estudantes e pelo representante da instituição durante as entrevistas realizadas.

\section{ASCENSÃO SOCIAL, SOLIDARIEDADE E PERTENCIMENTO RACIAL: CONTRADIÇÕES}

Em alguma medida, todas as narrativas coletadas apontaram como subsídios fundamentais para a elaboração das identidades raciais: a orientação familiar, a sociabilidade no bairro e na escola, a mídia em geral, episódios de discriminação e preconceito assim como estratégias de superação para essas situações. Contudo, no que tange ao pertencimento racial - entendido como o comprometimento com uma ideia de sujeito e de sociedade - procuramos identificar os elementos que relacionassem o discurso dos entrevistados ao projeto de ser negro apresentado em documentos da FZP e confirmado em entrevista com representante da instituição. Nesse processo, constatamos que a questão do trabalho enquanto meio para ascensão e inserção social apresentou-se como um dos elementos estruturantes.

As desigualdades educacionais consideradas como o núcleo do ciclo cumulativo de desvantagens a que os negros estão submetidos reverberam em todas as demais instâncias da vida produtiva desses indivíduos, estabelecendo relação direta entre trabalho e renda (GUIMARÃES, 2006). Tabulações feitas pelo LAESER $^{13}$, a partir dos microdados coletados nas regiões metropolitanas de Recife, Salvador, Belo Horizonte, Rio de Janeiro, São Paulo

${ }_{13}$ Laboratório de Análises Estatísticas Econômicas e Sociais das Relações Raciais, Boletim Tempo em Curso. Instituto de Economia- URFJ., ano II, v.. 2; n. 7, julho, 2010. 
e Porto Alegre para a Pesquisa Mensal de Emprego do IBGE indicaram que, em maio de 2010, o rendimento médio da população branca foi $46,8 \%$ maior que o rendimento da população negra. Trata-se de uma diferença considerável que, em parte, poderia ser justificada pelas diferenças de formação e pelos cargos geralmente ocupados por negros e brancos no mercado de trabalho. Porém, mesmo quando os dados analisam grupos brancos e negros com o mesmo número de anos de estudo, ainda se constata que os rendimentos de pretos e pardos são, no geral, $40 \%$ menores.

No quadro atual da economia brasileira, os postos de trabalho demandam formação e especialização dos trabalhadores na mesma proporção em que avançam as tecnologias de produção e de circulação de mercadorias. A ocupação desses postos fica condicionada, antes de tudo, à formação desses trabalhadores e é nesse momento que, concretamente, as desigualdades vivenciadas durante toda a vida escolar dos negros entram em um novo ciclo de repetições. Ao longo da trajetória escolar, a formação deficiente recebida restringe as possibilidades de trabalho da população negra concentrando-a em empregos menos qualificados e consequentemente com menor rendimento.

Eu trabalhei no banco e agora trabalho em uma multinacional e não tem negros. Eu estou trabalhando há oito meses lá e devo ter visto uns oito ou dez negros no máximo que trabalham lá. E tem muita gente. Estou falando da empresa em geral, tanto outras áreas e não tem.(Daniel)

O tipo de trabalho, além da renda, também proporciona status e um grau de poder a quem o exerce. Segundo a PNAD 2009, enquanto 6,1\% dos brancos são empregadores, apenas 1,7\% dospretos e 2,8\% dos pardos estão na mesma categoria. Quando analisamos a proporção de trabalhadores com emprego formal observamos que são os pretos e pardos a maioria dos empregados sem registro em carteira e também a maioria dos empregados domésticos (IBGE, 2010).

Nas melhores empresas, as provas são mais difíceis. Eu vejo esse retardo em termos de educação. No banco só entra como estagiário e para você fazer estágio tem que estar na faculdade. Fora os 20 [alunos] da faculdade [FZP] eu não vi mais nenhum. (Daniel)

Durante a ascensão profissional, mesmo ultrapassada a barreira da formação, a população negra ainda encontra dificuldade em ocupar melhores postos de trabalho, pois outros requisitos acabam sendo considerados, deixando os negros em situação de desvantagem.

Para Guimarães (2002), o fato de as discriminações não serem explícitas dificulta a identificação do fator racial, “diluído em uma série de características 
pessoais", como principal empecilho na contratação de pessoas negras. Mas não impedem que os sujeitos, atentos à situação, percebam a maneira como se processam:

Lógico que faz [diferença]! Se o meu currículo estiver bom e de uma pessoa branca estiver a mesma coisa que o meu, se o desempenho for igual, eu não acho que entro... Eu acho que a sociedade faz isso, $e$ eu nem sei se é só um racismo, um preconceito, mas já está inserido na sociedade, acho que as pessoas fazem até involuntariamente, já faz parte do RH [recursos humanos]. Por que ele [branco] pode chegar para ver um emprego de moicano e eu não posso ir de trança? De trança eu sou mal visto. (Vitor)

Isso eu tenho praticamente certeza. Já senti. As pessoas nunca falam... Se você estiver com o cabelo

feito escova você vai ser um pouco mais aceito. Essa empresa que eu fui fazer a entrevista com o cabelo trançado, um rabo de cavalo, e com lã azul?! [...]. Passou uma semana, duas e ela não ligou, na terceira ela ligou, mas queria que eu fosse no mesmo dia, porque ela tinha arrumado um estágio na USP e ia começar na segunda-feira, então ela teria um dia para passar todas as coisas para mim. Foi só por isso que ela me ligou. Eu sinto que faz uma diferença, viu. Você vê a cara da pessoa, tem gente que não consegue disfarçar. (Ana)

Os trechos anteriores denotam que os entrevistados não estão alheios às práticas de pouca aceitação de profissionais negros, que recaem sobre o último requisito não preenchido: a "boa aparência”, critério bastante subjetivo que faz parte do imaginário popular como uma referência a pessoas de pele clara e cabelos lisos, em uma total rejeição ao corpo negro.

[...] no caso brasileiro o corpo da pessoa também se impõe como uma marca visivel e é frequente privilegiar a aparência como condição primeira de objetivação e de julgamento, criando uma linha demarcatória, que identifica e separa, a despeito das pretensões de individualidade e de cidadania do outro. Então, a própria subjetividade e a dos demais esbarram no dado ostensivo da corporeidade cuja avaliação, no entanto, é preconceituosa. (SANTOS, 2000, p. 2)

Além do pretexto da "boa aparência", outro obstáculo na trajetória dos negros universitários é o renome da instituição de ensino onde estudam, pois muitos empregadores consideram esse um fator decisivo de contratação. As universidades tidas como de prestígio são justamente as instituições públicas que, devido à quantidade restrita de vagas e o modelo de seleção utilizado, menos recebem estudantes negros. Com isso retornamos ao início da discussão, em que os negros por terem uma escolarização básica de menor qualidade, acabam não tendo condições de concorrer em "pé” de igualdade com outros candidatos, oriundos de escolas particulares e cursinhos pré-vestibular. Algumas poucas instituições privadas compõem a lista de instituições mais valorizadas, porém essas também se encontram fora da realidade orçamentária de boa parte tanto da população negra como da população brasileira.

Como descrito em pesquisa realizada por Maria da Glória Callado (2007), a proposta pedagógica da FZP reconhece essa situação e tenta amenizá-la ao 
definir como uma das bases de seu projeto a parceria com empresas de grande porte para a implementação de programas de estágios nos quais seus alunos possam não só realizar atividades relacionadas à profissão escolhida como também se inserir no mercado de trabalho, atuando nas suas respectivas áreas de formação. Segundo representante da FZP, essa é uma estratégia organizada pelo grupo gestor da instituição para desconstruir paulatinamente a resistência que o mercado apresenta em relação ao profissional negro. Nesse sentido, as maiores parcerias para estágios estabelecidas pela FZP são com empresas do setor bancário ${ }^{14}$, que realizam seleções específicas entre os alunos da faculdade. Ao final do período de estágio existe a possibilidade de que esses alunos se efetivem na empresa, o que, de acordo com informação fornecida pela representante da FZP, tem ocorrido com uma frequência positiva.

Para muitos alunos, as perspectivas de trabalho que se apresentam estão muito além das possibilidades de ascensão social e profissional de suas famílias, o que tem gerado alguns descompassos entre alunos, familiares e amigos. No núcleo de apoio psicológico da FZP são vários os casos de queixas sobre a falta de apoio familiar e dos amigos, que teriam se afastado após o início da graduação e dos estágios. Esses alunos se sentem divididos entre a possibilidade de ascensão que se apresenta juntamente com possibilidades de novos círculos de amizades, novas formas de lazer, ascensão financeira, novo local de moradia. Enfim, são novos círculos de sociabilidade, diferentes dos que já estavam acostumados, com amigos do bairro que, geralmente, possuem trajetórias de vida muito próximas entre si.

O serviço de apoio psicológico da FZP oferece consultas individuais e uma vez por mês, são realizados encontros abertos à participação de todos os alunos interessados em discutir assuntos relacionados às suas vidas profissional, pessoal e acadêmica. Nos murais da faculdade cartazes convidam para os encontros com os seguintes dizeres: "A empresa onde você trabalha tem programa de diversidade, mas não aceita seu blackpower?", "Você trabalha no banco e seus amigos e família acham que você é banqueiro? Seus amigos te chamam de 'Mauricinho' e não te convidam mais para os programas?". A existência desse serviço demonstra o quanto essas questões são comuns àqueles alunos e indicam também mudanças na maneira como eles estão organizando seu pertencimento racial a partir de outro modelo de sujeito negro que, pelo visto, difere do modelo padrão das comunidades onde vivem.

Sotero (2010), em pesquisa realizada com universitários negros na cidade de

14 Os estágios em bancos e multinacionais são oferecidos aos alunos do curso de administração. 
Salvador, também constatou o distanciamento entre alunos e suas famílias durante esse processo de aquisição de status educacional e profissional e destacou o ingresso no mercado de trabalho como marcador importante dessa fase. Tanto os alunos pesquisados pelo autor, quanto os alunos que foram objeto desse estudo se encontram justamente numa fase em que, incisivamente, rompem com a estrutura de reprodução perpetuada em sua origem familiar.

No discurso da direção da FZP é nítida a noção de comprometimento com um projeto de sociedade em longo prazo, no qual as mudanças têm que ser iniciadas por alguém em algum momento e, nesse caso, segundo a representante da instituição entrevistada, a FZP acredita estar formando seus alunos para serem precursores nesse sentido.

A nossa preocupação é formar alguém que tenha essa visão de que tem que ajudar o outro, que tem que dar oportunidade. Não é criar coitadinhos, é dar a chance para mostrar que é capaz [...] tem que ter essa consciência de que não é prazeroso, não é orgulho para ninguém entrar por uma política de ação afirmativa, mas para que isso não aconteça mais, alguém vai ter que sofrer primeiro para que os outros não sofram, para que os outros vejam que dá para chegar lá sim, que é possivel fazer escolhas,

que tem que fazer sacrificios.(Lina Moreira)

Nem todos os alunos entrevistados responderam a essa expectativa. Mesmo assim, foi possível perceber que mesmo aqueles que não reproduzem tão fielmente a ideologia da faculdade reconhecem que os obstáculos não se encerram com a conquista do diploma universitário, pois o mercado de trabalho é ainda afetado pelo preconceito. E essa é uma questão que pareceu preocupar todos os alunos entrevistados.

Ela (FZP) abriu portas para muita gente. Eu mesmo se não estivesse aqui, nessa faculdade, não sei se eu estaria bem como estou hoje. E a maioria dos meus amigos da faculdade é bancário. Não sei se eles teriam essa oportunidade e se tivessem vindo de outro lugar, não iam ter a mesma ideia que a gente tem de que dentro da empresa tem que fazer a diferença (Daniel).

A ênfase dada à questão do trabalho dentro do projeto da Faculdade Zumbi dos Palmares enquanto elemento estruturante do pertencimento racial dos alunos denota certa dualidade na perspectiva da instituição. Ao mesmo tempo em que defende a ideia de sucesso e ascensão social como resultado do esforço individual, também prega a necessidade de união entre os negros enquanto grupo com características e objetivos comuns na reivindicação, perante Estado e sociedade, de medidas que corrijam - ou ao menos atenuem - injustiças sociais históricas. É certo que são posicionamentos que não se contrapõem em seu objetivo principal, de buscar a cidadania plena da população negra. Mas são posicionamentos habitualmente defendidos por 
dois grupos distintos: um que defende as cotas como medida de reparação social e outro que defende a meritocracia como meio de justiça social.

Dessa forma, o discurso que parece predominar no projeto oficial da FZP opera em um núcleo contraditório. De um lado, sob a lógica neoliberal, de autorregulação da sociedade, na qual o poder de consumo garantirá - ou ao menos permitirá - uma participação mais igualitária do negro. De outro, a solidariedade caracterizadora do pertencimento racial, que aparece como um amálgama para manter a coesão enquanto grupo racial, fazendo um contraponto ao individualismo. Trata-se, assim, de uma dinâmica que trabalha com a questão do negro na intersecção dessas duas frentes de ação: indivíduo e grupo.

Ao estimular a reconstrução/afirmação de uma identidade racial baseada tanto na revalorização de aspectos histórico-culturais, que remetem a ascendência africana, quanto em aspectos específicos da vida moderna em uma sociedade capitalista, a estratégia da FZP se apoia em duas plataformas conflitantes, mas que se entrecruzam dentro do contexto da instituição, criando uma trama muito particular de ações e subjetividades. Os depoimentos coletados apontam as contradições dessa dinâmica de reinventar a si mesmo e a sua raça e de se constituir em meio a um discurso que, ao mesmo tempo defende a necessidade de organização coletiva e solidariedade para o fortalecimento do grupo racial e valoriza a competitividade e o individualismo como parte do processo de ascensão social e econômica.

\footnotetext{
A gente está tendo a informação, e tem que ter informação, a gente está chegando, só que para chegar, a gente está deixando muita coisa para trás. (Vitor).

...você é da periferia e tenta voltar para periferia sem tentar mostrar que você não é um cara de fora, e lá fora você tem que mostrar que é da periferia, mas que veio para se manter. São dois mundos, foram uns cinco anos em que eu vivi em dois mundos, foi complicado, muitas vezes foi irônico, mas foi a minha vida...(Caio).

Quando eu estava no banco, junto com esse amigo meu, a gente tinha esse mesmo pensamento de que como os negros são privados - em algum ponto essa privação acontece - acho que os que estão dentro tem que mostrar que não tem sentido isso aí. Trabalhar não só para mim, mas para quem vai vir depois de mim. Serve meio que como um exemplo dentro da empresa(Caio).
}

À primeira vista, a relação curiosa entre aspectos tão incongruentes parece ter tocado um ponto-cego, inexplorado por grande parte dos movimentos negros por desconsiderarem a diversidade de expectativas dessa população. 
Esse discurso reproduzido constantemente pela direção e pelos professores da FZP parece conferir, ao mesmo tempo, estímulo e conforto ao seu grupo de alunos, pois estimula a busca pelo sucesso profissional, valorizando bastante o esforço e, de certo modo, a meritocracia; e ao mesmo tempo defende que, enquanto pares, esses alunos se protejem e se apoiem entre si, criando uma atmosfera de comunidade bastante cativante para os mesmos. Essa perspectiva de comunidade também é favorecida pela convivência com outros estudantes negros, em um ambiente que fomenta o debate das questões raciais comuns àqueles estudantes.

O contexto aqui apresentado e analisado comprovou-se propício ao desenvolvimento de um pertencimento racial, permitindo-nos conhecer a intimidade de um processo social que nos parece vem se espalhando pelo país, com uma perspectiva de reinvenção da raça negra. 


\section{Students at Faculdade Zumbi dos Palmares: reinventing racial belonging}

Abstract: This paper discusses the influence of the higher education experience in the resignification of racial belonging for black college students. In a qualitative study carried out from 2009 to 2011, students at Zumbi dos Palmares College (Faculdade Zumbi dos Palmares - FZP) were chosen for a case study. The institution - located in the city of São Paulo and connected to the black movement - was established in 2003 with the goal of providing alternative access to higher education as well as a space for black students to construct and affirm their racial identity through curricula marked by transversality. Beyond the discourse of FZP, the results of the research show that work and consumerism are important elements for the resignification of these students' racial belonging.

Keywords: Race Relations. Black People. Racial Belonging. Affirmative Action. Higher Education. 


\section{REFERÊNCIAS}

AMARAL, A.L. Pertencimento. In: Dicionário de Direitos Humanos. Escola Superior do Ministério Público da União. jun.2006. Disponível em: 〈http:// www.esmpu.gov.br/dicionario/tiki-index.php?page=Pertencimento». Acesso em: outubro 2011.

ARAUJO, T.C.N. A classificação de "cor” nas pesquisas do IBGE: notas para uma discussão. Cadernos de Pesquisa, n.63, p.14-16, nov.1987.

BURITY, J. A. Identidade e múltiplo pertencimento nas práticas associativas locais. In: Trabalhos para Discussão, n.108/2001. Recife: Fundação Joaquim Nabuco, 2001. Disponível em:^http://www.fundaj.gov.br/tpd/108.html\#_ ftn1>. Acesso em: setembro 2011.

CALADO, M. G. Como uma faculdade voltada para a população negra pode favorecer o enfrentamento da discriminação racial, o aumento da escolaridade e a inserção no mercado de trabalho desta população. 2007. Dissertação de Mestrado. Universidade São Marcos, São Paulo, 2007.

COSTA, S. A Construção Sociológica da Raça no Brasil. Estudos Afro-Asiáticos, ano 24, n1, pp. 35-61, 2002.

GOMES, J. B. B.. Ação Afirmativa e o Princípio Constitucional da Igualdade. Rio de Janeiro: Renovar, 2001.

GRIGOROWITSCHS, T. O conceito “socialização" caiu em desuso? Uma análise dos processos de socialização na infância com base em Georg Simmel e George H. Mead. Educação e Sociedade, v.29, n.102, p.33-54, Abr, 2008.

GUIMARÃES, A. S. A. Racismo e Antirracismo no Brasil. São Paulo: Fundação de Apoio à Universidade de São Paulo; ed. 34. 1999.

- Classe, raças e democracia. São Paulo: Fundação de Apoio à Universidade de São Paulo; Ed. 34. 2002.

- Como trabalhar com "raça” em sociologia. Educação e Pesquisa (USP), São Paulo, v. 29, n. 01, p. 93-108, 2003.

. Entrevista com Carlos Hasenbalg. Tempo Social, v.18, n.2, p.259268, Nov 2006.

HERINGER, R. Mapeamento de Ações e Discursos de Combate às Desigualdades 
Raciais no Brasil: estudos afro-asiáticos, v. 23, n. 2, 2001.

- Desigualdades raciais no Brasil: síntese de indicadores e desafios no campo das políticas públicas. Cad. Saúde Pública, v.18, p.57-65, 2002.

. Desigualdades raciais no Brasil: síntese de indicadores e desafios no campo das políticas públicas. Cad. Saúde Pública, v.18, p.57-65, 2002.

IBGE. Síntese dos Indicadores Sociais (SIS). Rio de Janeiro, 2010.

IPEA. Dinâmica Demográfica da População Negra Brasileira. Brasília: Comunicados do Ipea, n.91. maio, 2011.

MOEHLECKE, S. As políticas de diversidade na educação no governo Lula. Cadernos de Pesquisa, v. 39, n.137, p.461-487, maio/ago, 2009.

MOURÃO, L. M. B. Atitude Transdisciplinar - Pertencimento. In: CONGRESSO MUNDIAL DE TRANSDISCIPLINARIDADE, 2., 2005, Vitória - ES. II Congresso Mundial de Transdisciplinaridade, 2005.

MUNANGA, K. Mestiçagem e identidade Afro-brasileira. In: OLIVEIRA, I. (Org.). Cadernos PENESB 1 - relações raciais e educação: alguns determinantes. Niterói: UFF, Intertexto, p. 9-20, 1999.

PAIXÃO, M. et al (orgs.). Relatório Anual das Desigualdades Raciais no Brasil: 2009-2010. UFRJ: IE: LAESER, Ed. Garamond, 2011.

PEREIRA, J. B. B. O negro e a identidade racial brasileira. In: Racismo no Brasil. São Paulo: Peirópolis; ABONG, p. 65-72, 2002.

RIBEIRO, M. Análises e Propostas: as políticas de igualdade racial no Brasil. São Paulo: Fundação Friedrich Ebert, n. 35, abril, 2009.

SANSONE, L. Os objetos da identidade negra: consumo, mercantilização, globalização e a criação de culturas negras no Brasil. Mana, v.6, n.1, p.87119, abr, 2000.

SANTOS, M. Ser negro no Brasil hoje. Folha de São Paulo, Caderno Mais Brasil 501 d.c. 07/ maio/2000. Disponível em:<http://200.144.190.194/ neinb/files/Ser\%20negro\%20no\%20Brasil\%20hoje.pdf〉.

SCHWARCZ, L.M. Racismo no Brasil. São Paulo: Publifolha, 2001.

SILVA, A.da; SILVA, J.da; ROSA, W. Juventude negra e educação superior. In: CASTRO, J.A.; AQUINO, L.M.C.; ANDRADE, C. C. (Org.). Juventude e Políticas Sociais no Brasil. Brasília: IPEA, p.261-290, 2009. 
SILVERIO, V.; SOUSA, K.A. A Socialização e a Identidade: a escola e o dilema. In: ABRAMOWICZ, A.; GOMES, N.L. (Org.). Educação e Raça: perspectivas pedagógicas e estéticas. Belo Horizonte: Autêntica, p. 97-120, 2010.

SOTERO, E. C. Trajetória Educacional de Jovens Negros Beneficiados por Políticas de Ação Afirmativa na Cidade de Salvador. 2010. Dissertação de Mestrado. Faculdade de Filosofia, Letras e Ciências Humanas, Universidade de São Paulo, 2010.

SOUZA, J. Raça ou classe? Sobre a desigualdade brasileira. São Paulo: Lua Nova, n.65, p.43-69, 2005.

TELLES, E. Racismo à Brasileira: uma nova perspectiva sociológica. Rio de Janeiro: RelumeDumará, 2003.

RECEBIDO: Dezembro de 2012.

APROVADO: Abril de 2013 . 